\section{¿AMAZON EN CHILE?}

Anett Erdmann, académica FEN UAH

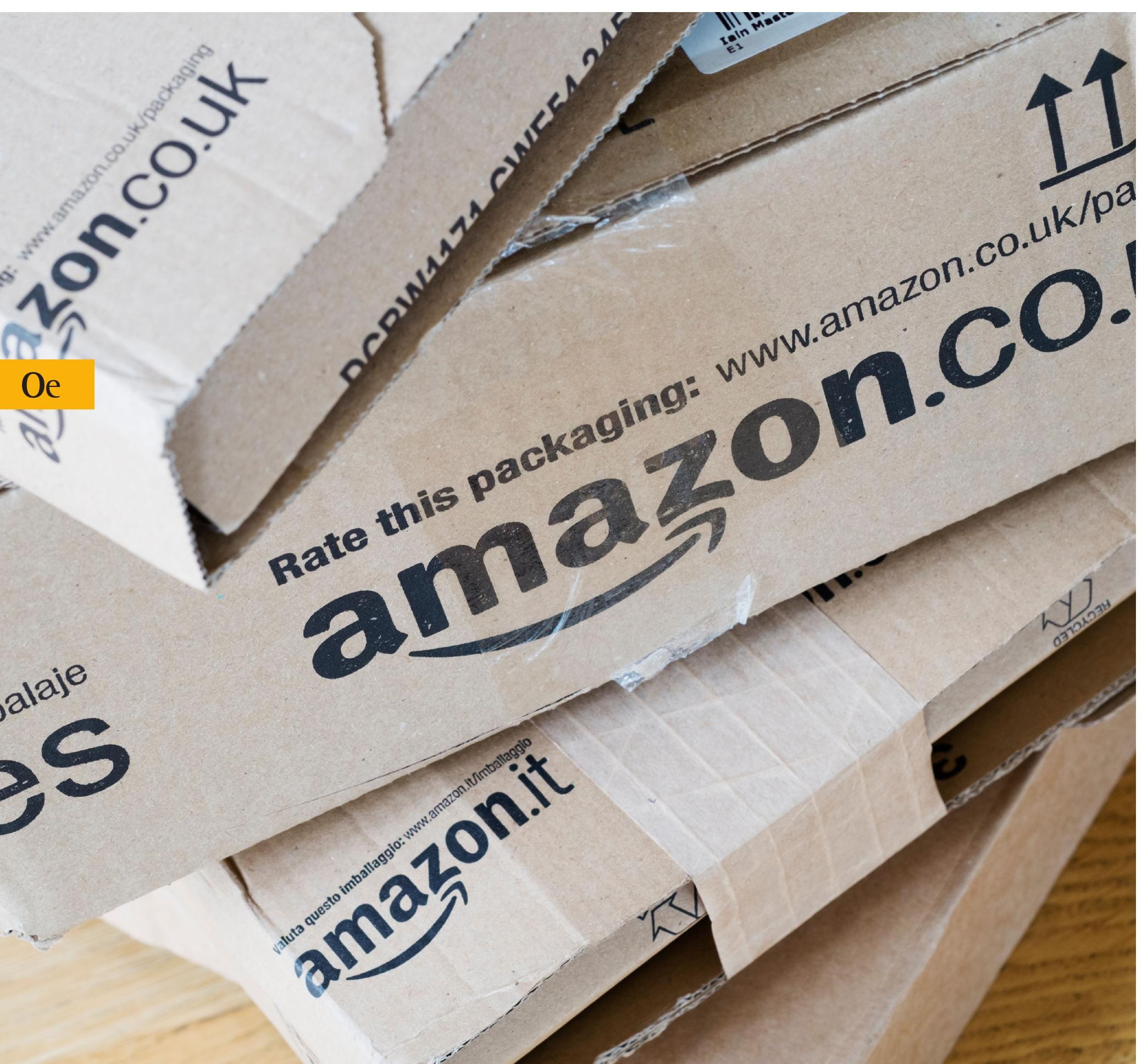

Durante todo el 2017 hubo varios rumo-
res en la prensa sobre la posible entrada Amazon en Chile, especialmente trasmitidos como una potencial amenaza para las enpresas chilenas

La entrada del coloso de comercialización online en otros paises ha puesto el listón de la calidad de venta en linea muy alto - en terminos de variedad, rapidez y servicios adicionales- pero sobre
sobre los precios.

Este artículo se refiere a ciertos aspectos concretos de la estrategia de Amazon y sobre las implicaciones que supondrian para Chile la entrada de Amazon si finalmente los rumores se convierten en realidad.

Pero, ¿qué es Amazon? Amazon es un empresa estadounidense que opera internacionalmente como comerciante y como plataforma de ventas online. La empresa empezo hace dos decadas con la venta de un gran variedad de libros, $y$ desde entonces $h a$
ido penetrando paulatinamente en multitu ido penetrando paulatinamente en multitud de sectores, como por ejemplo el textil, video juegos, juguetes, muebles, joyeria, alimentamundias act lide y presidente Jeff Bezos una de las person más ricas del mundo.

Con enfoque en los a otros aspectos, es muy destacable su servicio "Amazon Prime", una tarifa plana en la cual mediante una cuota anual los clientes disgrutan para sus compras de entregas exprés su servicio "Amazon Prime Now", orientado productos de alimentación, el plazo de entrega gratuita es inferior a 2 horas. Adiciona mente esta membresla aporta al consumidor otros beneficios como películas a la carta

Con enfoque en las empresas, Amazon en por mayor parcia ro coma produch taforma de ventas online muestra productos ofrecidos por terceros Adicionalmente ofrece la posibilidad a otras empresas que usan plataforma de contratar un servicio integra de logistica que incluye el almacenamiento la gestión de la distribución de sus productos ("Fulfillment by Amazon"),

En la actualidad se están realizando numerosos estudios académicos sobre el comportamiento estratégico de Amazon y su
impacto en el mercado. A continuación nos impacto en el mercas
centramos en dos:
Houde, Newberry y Seim (2017) han racional usar el servicio de distribución de

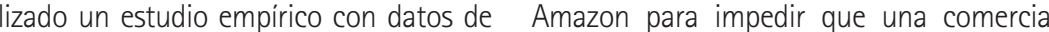
ventas de Amazon en el cual argumentan - lizacion propia de este producto sea rentaque uno de los pilares de la eficiencia logis- ble. A parte de esto, una alternativa para las tica de la empresa se basa en la creación de grandes empresas que usan la plataforma de una red de distribución optima que permite Amazon es regularlo contractualmente a tra

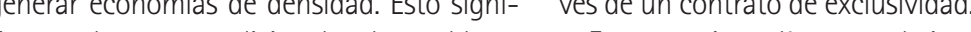
y maner un ticas descentralizadas se ven conpensodos cafor la stuación en la que Amazon "plapor el ahorro en costos de distribución que "comerciate" frente a los de las comazen supone la cercania a suministradores $y$ con- Un ejemplo reflejado en la prensa fue el caso sumidores Esta eficiencia logistica permite a de la venta de "Fire TV" (un dispositivo para el la empresa ofrecer precios ajustados $y$ rapi- televisor de Amazon como comercinte) exdez en la entrega del producto Los precios cluyendo la opción de comprar dispositivos a te aumentan la demanda mentras que la rapidez en la entrega, signo de calidad, parece estar sobrevalorada y no (a) impacto directo en la demanda. En (no incluido en el estudio citado), esta última afirmación es relativa. En el caso de España, observamos que después de la irrupción del servicio "Amazon Prime Now" muchas de las grandes cadenas de supermercados paulathen Amazon entró con dicho servicio en paña inicialmente con una cuota anual de membresia y el pedido minimo para compras de productos alimentarios online muy bajo en comparación con la competencia. De esta forma se aseguró en el corto plazo una rápida aceptación por parte de los consumidores. Pasada la fase de captar clientes, ahora ha adaptado sus condiciones hacia arriba en terminos de pedido minimo, convergiendo con las condiciones actuales de prensa sobre una posible alza de la cuota nual de membresia.

Segundo, los académicos Zhu y Liu (2016) Sen datos de siendo plaforma y comerciante a que Amazon podria tener incentivos para imitar algunos productos que se venden a través de su plataforma y venderlos además como comerciante.

Los mismos autores también destacan que el incentivo disminuye si Amazon ya es el operador de toda la logistica del producto a traves de su servicio "Fulfiliment by Amazon", con el cual Amazon recibe una consión adicional por producto vendido. Esto sugiere que puede ser una estrategia

similares de Apple o Google.

Como contrapartida, no hay que olvidar que la empresa sigue una estrategia de largo plazo que implica mantener las relaciones con las empresas que usan su servicio lo que desincentiva la imitación que podri evar a sus clientes a abstenerse del uso de

¿Y qué podemos esperar para Chile? Todavia no existen datos concretos que mercado chileno, qué servicios ofrecerá, cuáles serán sus alianzas con empresas naA falta de realizar un estudio difer sectores y con más detalles, por el momento únicamente podemos avanzar en lo que esperamos a nivel microeconómico sobre entrada de Amazon en Chile: que incentive la competencia en precios y por tanto benefic al consumidor.

Esperamos que la respuesta del concenrado mercado de multitiendas que ya operan online, consista al menos, en una mejora Para las empresas que no disponen de

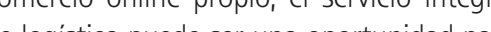
legar al consumidor digital.

Documento de trabajo "Economies of Density in Center Network" de los profesores Jean-Franceis Houde (Universidad Cornell), Peter Newberry Universidaa Estatal de Pensilvanial y Katja Seim Universidad de Pensilvania). plementors: An Empirical Look at Amazon com" os profesores Feng Zhu (Universidad de Harvard) 